\title{
Medicina Tradicional en la comunidad garífuna de Orinoco
}

Forn Prudencia López Stephen

En la comunidad de Orinoco, municipio de Laguna de Perlas, RAAS, existe una iniciativa por rescatar e integrar la medicina tradicional al modelo de Salud. Esta investigación sistematiza esta práctica ancestral, con el objetivo de fortalecer este importante esfuerzo que pretende enriquecer el actual modelo de Salud en la región, con los saberes ancestrales de la población garífuna de Orinoco.

\section{Plantas medicinales utilizadas}

Las plantas medicinales usadas de forma natural por esta población son 28: hojas de albahaca, wandring dew, kaasnipata, phisic nat, casaba marble, noni, sorosi, sweet tic, piss a bed, guanábana sour sap, wild shade, zacate limón, hojas de peras, hojas guayaba, hojas de marañón, ram goat dashalan, hoja de tatacu, chany root/cuculmeka, malva leaf, vorvine leaf, cow foot, sleeping pricle, cow tonge, bitan sweet, coconut tree root, single bible or captice, heal and draw, locas bark.

Para encontrar las plantas medicinales, como ram goat dashalam. chainy root, vervine, bitan and sweet, wild shade, locas bark $y$ heal and draw, los médicos tradicionales y comunitarios tienen que viajar largas distancias para conseguirlas.

\section{Enfermedades tratadas con medicina tradicional}

Infecciones renales, fiebre, asma, diarrea, tos, cefalea, dolor de cabeza, roncha mala, úlcera estomacal, anemia, parásitos, vómito, próstata, conjuntivitis, enfermedades de la piel, dolor de muela, diarrea con sangre, hemorragia, heridas, hipertensión y desnutrición.

Tipos de enfermedades, nombres de las plantas, formas de prepararlas y aplicación

\begin{tabular}{|c|c|c|c|}
\hline Enfermedades & Nombre de la Planta & Preparación & Aplicación \\
\hline Infección renal. & $\begin{array}{l}\text { Hojas de albahaca, wandrin } \\
\text { jew, kaasnipata leaves, } \\
\text { phisicnat leaves, cassava } \\
\text { marble, nonie leaves. }\end{array}$ & $\begin{array}{l}\text { Algunas hojas de albahaca, hojas de } \\
\text { wandrin jew, hojas de kaasnipata, } \\
\text { siete hojas de phisicnat, siete hojas de } \\
\text { cassava marble y siete hojas de nonie. } \\
\text { Hervirlas juntas en un galón de agua } \\
\text { por quince minutos. }\end{array}$ & $\begin{array}{l}\text { Adultos: tomar un vaso } \\
\text { tres veces al día. Niños: } \\
\text { medio vaso tres veces } \\
\text { al día. }\end{array}$ \\
\hline Fiebre. & $\begin{array}{l}\text { Surusi, sweet stick, zacate } \\
\text { limón, pizabeth leaves, hojas } \\
\text { de guanabana, while shade } \\
\text { leaves, cuatro limones. }\end{array}$ & $\begin{array}{l}\text { Hervir las hojas en medio galón de } \\
\text { agua por treinta minutos, todos los } \\
\text { ingredientes juntos; cortar el limón } \\
\text { en dos partes y echarlas cuando esté } \\
\text { hirviendo. }\end{array}$ & $\begin{array}{l}\text { Se toma como agua. } \\
\text { Bañar al enfermo con } \\
\text { el preparado cuando } \\
\text { éste esté tibio. }\end{array}$ \\
\hline
\end{tabular}




\begin{tabular}{|c|c|c|c|}
\hline Asma. & $\begin{array}{l}\text { Hojas de cilindre, hojas de } \\
\text { pera, tres dientes de ajo, } \\
\text { cebolla, miel. }\end{array}$ & $\begin{array}{l}\text { Hervir, en un litro de agua, diez hojas } \\
\text { de cilindre, tres de pera y tres dientes } \\
\text { de ajo. También se puede utilizar una } \\
\text { cabeza de ajo, una cebolla entera y } \\
\text { miel. Se machaca el ajo y la cebolla, se } \\
\text { mezclan con la miel y se deja reposar. }\end{array}$ & $\begin{array}{l}\text { Adultos: medio vaso } \\
\text { tres veces al día. Niños: } \\
\text { una cucharada tres } \\
\text { veces al día. }\end{array}$ \\
\hline Diarrea. & $\begin{array}{l}\text { Hojas de guayaba y cáscara } \\
\text { de marañón. }\end{array}$ & $\begin{array}{l}\text { Hervir las hojas con la cáscara en } \\
\text { medio galón de agua. }\end{array}$ & $\begin{array}{l}\text { Tomar medio vaso } \\
\text { tres veces al día. }\end{array}$ \\
\hline Tos. & Ram goat dashalan. & Hervir siete hojas en un litro de agua. & $\begin{array}{l}\text { Adultos y niños } \\
\text { tomarlo como agua. }\end{array}$ \\
\hline $\begin{array}{l}\text { Cefalea, dolor de } \\
\text { cabeza. }\end{array}$ & Hojas de guanábana ice leaf. & & $\begin{array}{l}\text { Se colocan atadas en } \\
\text { la cabeza. }\end{array}$ \\
\hline Roncha mala. & Hojas de tatacu. & Machacar las hojas. & $\begin{array}{l}\text { Aplicar sobre la parte } \\
\text { afectada tres veces al } \\
\text { día }\end{array}$ \\
\hline Dolor de cabeza. & Malva, alcohol o menticol. & $\begin{array}{l}\text { Machacar la malva con un poquito de } \\
\text { agua y echar alcohol o menticol. }\end{array}$ & $\begin{array}{l}\text { Aplicar la preparación } \\
\text { en la cabeza tres veces } \\
\text { al día. }\end{array}$ \\
\hline Úlcera estomacal. & Single biblel captice. & $\begin{array}{l}\text { Se machaca y se pone en un pichel de } \\
\text { agua. }\end{array}$ & $\begin{array}{l}\text { Se toma como agua, } \\
\text { un pichel diario por } \\
\text { quince días. }\end{array}$ \\
\hline Anemia. & Chainy root y leche. & $\begin{array}{l}\text { Hervir un puño de chainy root. Antes } \\
\text { de tomarlo mezclar con leche. }\end{array}$ & $\begin{array}{l}\text { Tomar un vaso tres } \\
\text { veces al día. }\end{array}$ \\
\hline Worms /parásitos. & $\begin{array}{l}10 \text { vervine leaves, dos peg of } \\
\text { garlic. }\end{array}$ & $\begin{array}{l}\text { Hervirlos por quince minutos en tres } \\
\text { tazas de agua. }\end{array}$ & $\begin{array}{l}\text { Tomarlo cuando se } \\
\text { tenga sed. }\end{array}$ \\
\hline Parásitos. & $\begin{array}{l}\text { Vervine (10 leaves), coconut } \\
\text { cream, salt. }\end{array}$ & Mezclarlas con un poco de sal. & $\begin{array}{l}\text { Adultos: una } \\
\text { cucharada una vez } \\
\text { al día. Niño: una } \\
\text { cucharadita una vez } \\
\text { al día. }\end{array}$ \\
\hline Vómito. & $\begin{array}{l}\text { Promenta seed, cinannon } \\
\text { and chicken guisad. }\end{array}$ & $\begin{array}{l}\text { Hervirlo todo en dos tazas de agua } \\
\text { por diez minutos. }\end{array}$ & $\begin{array}{l}\text { Adultos: una } \\
\text { cucharada tres veces } \\
\text { al día, Niño: una } \\
\text { cucharadita tres veces } \\
\text { al día hasta dejar de } \\
\text { vomitar. }\end{array}$ \\
\hline Próstata. & $\begin{array}{l}\text { Miel, manzanilla, bitam } \\
\text { sweet. }\end{array}$ & $\begin{array}{l}\text { Hervir juntos estos dos productos, y } \\
\text { antes de tomar la poción mezclar con } \\
\text { la miel. }\end{array}$ & Tomarlo como agua. \\
\hline
\end{tabular}




\begin{tabular}{|c|c|c|c|}
\hline Conjuntivitis. & Pizabeth & $\begin{array}{l}\text { Machacarlo y verter el jugo en un } \\
\text { gotero para su aplicación en los ojos. }\end{array}$ & $\begin{array}{l}\text { Aplicarlo tres veces } \\
\text { al día. }\end{array}$ \\
\hline $\begin{array}{l}\text { Enfermedades de } \\
\text { la piel. }\end{array}$ & Surusi & $\begin{array}{l}\text { Machacarlo y aplicarlo en el área } \\
\text { afectada. }\end{array}$ & $\begin{array}{l}\text { Aplicar } 3 \text { veces al día } \\
\text { en el área afectada. }\end{array}$ \\
\hline Dolor de muela. & Cow foot 3 root scrape it & $\begin{array}{l}\text { El polvo de la raíz ya raspado } \\
\text { introducirlo en el agujero de la muela } \\
\text { cariada. }\end{array}$ & $\begin{array}{l}\text { Una vez al día } \\
\text { hasta que el dolor } \\
\text { desaparezca. }\end{array}$ \\
\hline Diarrea con sangre. & $\begin{array}{l}3 \text { young coconut cut each } \\
\text { one in } 3 \text { pieces } 4 \text { pieces } \\
\text { of coconut } 3 \text { root, cut it } \\
\text { up small6 guava leaves } 4 \\
\text { guava buds, } 1 \text { little bag with } \\
\text { sinimont-esencia. }\end{array}$ & $\begin{array}{l}\text { Hervirlo en un litro de agua por } \\
\text { treinta minutos, luego echarle un } \\
\text { poco de esencia. }\end{array}$ & $\begin{array}{l}\text { Adutos: } 1 / 4 \text { de vaso } \\
\text { tres veces al día. }\end{array}$ \\
\hline Hemorragia. & $\begin{array}{l}\text { Wandrin jew, kaasnipata, } \\
\text { cassava marble, sleeping } \\
\text { prickel, cow tong, fisic not. }\end{array}$ & Hervir todo junto. & $\begin{array}{l}\text { Comenzar primero } \\
\text { con un vaso y, } \\
\text { después de media } \\
\text { hora, tomar otro. }\end{array}$ \\
\hline Cualquier herida. & Heall and draw. & Se machaca y se le saca el jugo. & $\begin{array}{l}\text { Se aplica el jugo en la } \\
\text { herida hasta que ésta } \\
\text { se cure. }\end{array}$ \\
\hline Desnutrición. & $\begin{array}{l}\text { Locas bark, chainy root and } \\
\text { sweet. }\end{array}$ & Hervir las tres plantas medicinales. & $\begin{array}{l}\text { Se toma como agua } \\
\text { por seis meses } \\
\text { hasta que se cura la } \\
\text { desnutrición. }\end{array}$ \\
\hline Hipertensión. & Wild shade. & $\begin{array}{l}\text { Se hierven siete hojas. Se puede } \\
\text { también masticar } 3 \text { hojas sacándole el } \\
\text { jugo y botando el residuo. }\end{array}$ & $\begin{array}{l}\text { Se toma por meses, } \\
\text { diariamente, como } \\
\text { agua. }\end{array}$ \\
\hline
\end{tabular}

Nota: El 100/\% de los médicos tradicionales refieren que, al hervir las plantas o hierbas u hojas, ponen mientras tanto, encima del recipiente, una cruz hecha de palo verde y oran al Todopoderoso para que sea el sanador del paciente. Consideran esto un secreto de sanación.

\section{Médicos tradicionales de Orinoco}

Simón Zenón Morales, Simón Cash Estrada, Justo López Davis, Aldrick Cayasso Bennett, Elma Luisa Hebbert Estrada. Aunque esta última sólo atiende partos. 


\section{BIBLIOGRAFIA}

1. Cáceres, Alejandro. 1996. Plantas de Uso Medicinal en Guatemala. Edición Universitaria. Universidad de San Carlos de Guatemala. 402 pág.

2. Constitución Política de la República, Titulo 1, Capitulo Único, Articulo 5, Párrafo 3.

3. Davis, Rosa et al (2001). Historia de la comunidad Garifuna de Orinoco. URACCAN, IPLCC.

4. González, Ligia M; Huete Mendoza, Maximina; Palacios, Ligia M; López, Mairena Eugenia. (2004). Impacto de las Plantas Medicinales en la Salud Humana en la Colonia Los Ángeles Nueva Guinea, URACCAN, Nueva Guinea.

5. Instituto Interamericano de Derechos Humanos y Organización Panamericana de la Salud. (2006). Medicina Tradicional y Medicina Convencional, San José, Costa Rica.

6. López, Victorina y Loyda López. (2009). Importancia del uso de la Medicina Tradicional. Tesis para obtener el título de bachiller.

7. Ley No. 28 de (Cap. II, Arto. No.8, párrafo No. 5).

8. UNESCO (2008). Proceso de Identificación y Recomendaciones de Salvaguardia (PIRS) de las manifestaciones del Patrimonio cultural Inmaterial.

9. UNESCO (2002). Glosario sobre patrimonio cultural inmaterial.

10. UNESCO (2009). Informe Línea de Base para el programa de Revitalización Cultural y Desarrollo Productivo Creativo de UNESCO en la Costa Caribe de Nicaragua. Primera Versión.

11. Zhang,Xiaonu. (2010). Medicina Tradicional, Medicamentos Esenciales y Politica Farmacéutica CEDM. OMS, Ginebra. 